\title{
Zur Entstehung der Netzhautspaltung bei intraokularem Aderhautsarkom.
}

\author{
Von
}

Konsiliararzt Kais. Rat Dr. Theodor Ballaban,

k. u. k. Regimentsarzt, Chelarzt der Augenabteilung in k. u. K. Reservespital Lemberg III.

E. Fuchs ${ }^{1}$ ) ist in einer ausführlichen Arbeit über das Sarkom der Aderhaut auch auf die zuerst von Bruns ${ }^{2}$ ) beobachtete Spaltung der über dem Aderhauttumor gelegenen Netzhaut in zwei Lamellen näher eingegangen. Fuchs gibt dieser Spaltung der Netzhaut, welche in den von ihm beobachteten und aus der Literatur angeführten Fällen immer in der Zwischenkörnerschicht erfolgt, folgende Erklärung:

Beim Einwuchern der Geschwulst in die Netzhaut wird zuerst nur die äußere Schicht derselben durch Geschwulstmasse ersetzt. Der Rand der äußeren Schicht verlötet sich mit dem Tumor, und mußte dann, da die Tumoroberfläche sich bei Wachstum beständig vergrößert und die Verwachsungsstelle damit von der supponierten Mitte der Durchwucherung immer weiter abrückt, dadurch gewissermaßen eine Abreißung der inneren von den äußeren Netzhautschichten erfolgen. Es ist nach Fuchs' Ansicht also diese Netzhautspaltung erst möglich, wenn der Tumor schon die äußeren Netzhautschichten durchwuchert und zur Dehiszenz gebracht hat.

Fuchs' Erklärung unterscheidet sich meines Erachtens nur unwesentlich vou der Erklärung, die Bruns, der zuerst einen derartigen Fall beschrieben, gegeben hat. Auch bei Bruns entsteht die Spaltung nach der Durchwachsung der äußeren Netzhautschicht, auch mechanisch aber durch direktes Andrängen der an der Spitze am stärksten wachsenden Geschwulst, welche die inneren Netzhautschichten immer weiter von der Aderhaut abdrängt, während die äußere durch ihre Verwachsung mit der Neubildung festhaften bleibt.

Beide Erklärungen scheinen mir für jene Fälle hinfällig, an denen eine Netzhautspaltung über dem Tumor besteht, ohne daß die Netzhaut in einer ihrer Schichten von der Neribildung durchwuchert ist.

Für diese paßt meines Erachtens nur die von mir ${ }^{3}$ ) gegebene Erklärung. Da sie an dieser Stelle veröffentlicht wurde, möchte ich hier von nevem auf dieselbe hinweisen.

In meinem Falle war die Netzhaut in kleiner Ausdehnung mit dem Turnor (Sarkom der Aderhaut) innig verwachsen, an der Stelle der Vex- 
wachsung in zwei, durch einen großen cystenartigen HohIraum getrennte Blätter geschieden, deren äußeres aus größtenteils ausgezogenen Zellen mit bindegewebiger Zwischenmasse besteht, während das innere Blatt, drei- bis fünfmal so dick wie die äußere Schicht, viel besser erhalten ist und die innere Netzhautschicht mit allenthalben noch gut erhaltener innerer Körnerschicht betrifft. Die Pigmentepithelzellen sind in der Verwachsungsstelle nur zum Teil mehr erhalten, die Trennung zwischen Geschwulst und äußerer Netzhautlamelle ist aber eine absolut scharfe. Als wichtiger Befund wurde erhoben, daß an einem Rande der cystenartigen Netzhautteilung peripherwärts rasch an Größe abnehmende kleinere eystenartige Räume in der Zwischenkörnerschicht sich fanden, analog jenen, die wir bei der sog. cystoiden Entartung der Netzhaut so regelmäßig finden. Es war also in meinem Falle die Spaltung der Netzhaut in zwei Lamellen, die anscheinend von Knies ${ }^{4}$ ) zuerst ausführlicher gewürdigt wurde, einer Einwachsung des Tumors in die Netzhaut vorausgegangen, und ich mußte aus dem ganzen Befunde schließen, daß es sich um ein Analogon zu der schon genannten cystoiden Entartung der Netzhaut handeln muß, welches nur zufolge besonderer Umstände, die hier zu erörtern keinen Zweck hätte, zu einer besonderen Größe und Form gediehen ist. Daß diese Erklärung ihre Wahrscheinlichkeit für sich hat, scheint sich mir auch daraus zu ergeben, daß, wie auch in einem von Fuchs zitierten Falle (S. 70, 1), in der Zwischenkörnerschicht die cystoide Entartung sich vorfindet.

$\mathrm{Zu}$ der bald nach meiner Veröffentlichung erfolgten Mitteilung von Reis ${ }^{5}$ ) möchte ich anführen, daß ich die der cystoiden Entartung analoge Veränderung der Netzhaut über dem Tumor durchaus nicht etwa als eine Erkrankung sui generis aufgefaßt habe, sondern auf die gleiche Ursache wie die cystoide Degeneration überhaupt zurückführe.

Für die weitere Ausdehnung der cystoiden Räume habe ich osmotische Vorgänge verantwortlich gemacht.

\section{Literatur.}

1. Fuchs, E., Utber Pigmentierung, Melanom und Sarkom der Aderhaut. Archiv f. Opthalmol. 94, 43. 1917 .

2. Bruns, Beiträge zur Lehre von den Aderhautsarkomen. Archiv f. Ophthalmol. 54, 563. 1902.

3. Ballaban, Th., Intraokulares Sarkom. Arehiv f. Ophthalmol. 63, 69. 1906.

4. Knies, 16 Falle von Aderhautsarkom nebst epikritischen Bemerkungen. Archiv f. Augenheilk. 6, 158. 1877.

5. Reis, Intraokulare Blutung und Aderhautsarkom. Zeitsohr. f. Augenheilk. 20, 311. 1908. 